\title{
Chiral biomarkers and microfossils in carbonaceous meteorites
}

\author{
Richard B. Hoover ${ }^{*}$ \\ Space Science Office, Mail Code 62, NASA/Marshall Space Flight Center, Huntsville, AL 35812
}

\begin{abstract}
Homochirality of the biomolecules (D-sugars of DNA and RNA and L-amino acids of proteins) is a fundamental property of all life on Earth. Abiotic mechanisms yield racemic mixtures $(\mathrm{D} / \mathrm{L}=1)$ of chiral molecules and after the death of an organism, the enantiopure chiral biomolecules slowly racemize. Several independent investigators have now established that the amino acids present in CI1 and CM2 carbonaceous meteorites have a moderate to strong excess of the $L$-enantiomer. Stable isotope data have established that these amino acids are both indigenous and extraterrestrial. Carbonaceous meteorites also contain many other strong chemical biomarkers including purines and pyrimidines (nitrogen heterocycles of nucleic acids); pristine and phytane (components of the chlorophyll pigment) and morphological biomarkers (microfossils of filamentous cyanobacteria). Energy dispersive X-ray Spectroscopy (EDS) analysis reveals that nitrogen is below the detectability level in most of the meteorite filaments as well as in Cambrian Trilobites and filaments of 2.7 Gya Archaean cyanobacteria from Karelia. The deficiency of nitrogen in the filaments and the total absence of sugars, of twelve of the life-critical protein amino acids, and two of the nucleobases of DNA and RNA provide clear and convincing evidence that these filaments are not modern biological contaminants. This paper reviews the chiral, chemical biomarkers morphological biomarkers and microfossils in carbonaceous meteorites. This paper reviews chiral and morphological biomarkers and discusses the missing nitrogen, sugars, protein amino acids, and nucleobases as "bio-discriminators" that exclude modern biological contaminants as a possible explanation for the permineralized cyanobacterial filaments found in the meteorites.
\end{abstract}

Keywords: Biomarkers, chirality, carbonaceous meteorites, Orgueil, Murchison, microfossils, EDS, protein amino acids

\section{INTRODUCTION}

The study optical activity and chirality in nature was initiated in 1811 by Arago, ${ }^{1}$ as he observed colors in sunlight through asymmetric quartz crystal between crossed polarizers. Biot explained the phenomenon of optical activity as due to optical rotation of the plane of polarization of linearly-polarized light and optical rotary dispersion (unequal rotation of the polarization plane at different wavelengths). ${ }^{2}$ By convention, clockwise rotation as one faces the light source is "positive" or dextrorotary $(D-)$ and counterclockwise rotation as "negative" or levorotary ( $L$-). In 1848, Louis Pasteur observed that chemical (abiotic) reactions produced racemic mixtures crystals of sodium ammonium paratartrate with equal numbers of the two forms from aqueous solutions. (See Flack ${ }^{3}$ for a review of Pasteur's research on chirality). Pasteur recognized that the crystal structures represented the underlying asymmetry of the molecules that existed in forms that were non-superimposable mirror images of each other (chiral enantiomers). After carefully separating the two types of crystals he discovered that when they were dissolved the resultant solutions exhibited optical activity and rotated the plane of polarization of light in opposite directions by the same amount. Pasteur's discovery of chirality of organic molecules with asymmetric location of group-radicals and recognition that critical biomolecules of living organisms possessed a molecular asymmetry that included exclusively only one of the enantiomers (biological homochirality) was profound. It led him to speculate that the origin of the chiral biomolecules might hold the key to the nature of life. There is little doubt that the homochirality of macro-molecules is a signature of life as we know it. After death of the organism, the distribution of chiral biomolecules slowly changes. Sugars and unstable amino acids are consumed; less stable amino acids are destroyed or converted into more stable forms and they all begin to racemize.

*Richard.Hoover@NASA.GOV; phone 1256 961-7770; fax 1 256-961-7524 
Homochirality of biological stereoisomers is lost after death as the amino acids, sugars, and other chiral biomolecules slowly become racemic over different geological time scales. It has been shown by the study of fossils (e.g., hair/tissues from mummies and mammoths, amber encapsulated insects, fossil shells and invertebrates, and teeth/bones of mammals and dinosaurs) that some amino acids remain with a slight to moderate enantiomeric excess for millions of years. Diagenetic pathways slowly convert chlorophyll and other biomolecules into geologically stable breakdown products, such as pristine, phytane, metalloporphyrins and other isoprenoid and terpenoid alkanes. Polycyclic aromatic hydrocarbons (PAH's) and carbonate globules are weak biomarkers since they are easily produced by abiotic mechanisms. On the other hand, recognizable microfossils, chiral amino acids with moderate to strong enantiomeric excess and the diagenetic breakdown products of chlorophyll, nucleic acid bases and many other complex life-critical biomolecules are strong biomarkers. They are known to be produced by biology and there are not known to occur in nature from abiotic production mechanisms. All of these strong biomarkers have been detected by independent researchers in the CI1 and CM2 carbonaceous meteorites. Furthermore, the filamentous microfossils found in meteorites exhibit abnormal levels of many biogenic elements, such as nitrogen, carbon, sulfur and phosphorus. Sugars and many other unstable, but very abundant, life-critical, biomolecules have never been detected in the carbonaceous meteorites. These common biomolecules would certainly be present if the meteorites were contaminated by modern biology, and hence they represent modern bio-contaminant discriminators. The strong biomarkers and contaminant bio-discriminators found in CI1 and CM2 carbonaceous meteorites include:

Chlorophyll skeletal structures and diagenetic products: Porphyrins, pristine, and phytane are present in the meteorites but the photosynthetic pigments (chlorophyll $a$. $b$ or $c$ ) themselves. Life-critical electron transport proteins (cytochromes) and co-enzymes (NAD, NADH, ATP) are also not found in carbonaceous meteorites.

Sugars and structural polysaccharides: Present in all living organisms but not detected in meteorites.

Protein amino acids: Eight found-some with enantiomeric excess- 12 protein amino acids are missing.

Nucleic acid bases: Adenine, Guanine \& Uracil have been detected. However, Cytosine and Thymine are missing and DNA and RNA molecules have never been found in the carbonaceous meteorites.

Carbonaceous meteorites contain a host of strong biomarkers that would be interpreted as clear and convincing evidence of biology if found in any terrestrial rocks. Many other geologically unstable, life-critical biomolecules that are present in all living and recently dead organisms (e.g. DNA, RNA, ATP, NADH, proteins and enzymes) have never been detected in carbonaceous meteorites. These biomolecules are also typically absent from mineralized remains of Proterozoic and Archaean cyanobacterial filaments, trilobites, dinosaur bones and teeth and many other undeniably biological remains found in Earth Rocks These biomolecules are present in all living organisms and found at easily detectable levels even in the remains of Holocene and Pleistocene organisms. The absence of these biomolecules in carbonaceous meteorites provides strong evidence that the recognizable filaments found in these meteorites are not modern biological contaminants that invaded the stones after they landed on Earth.

\section{CHEMICAL BIOMARKERS AND BIO-DISCRIMINATORS}

\subsection{Enantiomeric excess of chiral amino acids}

Amino acids have an $\alpha$-carbon atom bonded to one hydrogen atom, a carboxyl group, and a variable $\mathrm{R}$ group that determines which particular amino acid it is. There are 20 common amino acids that are monomers of protein polypeptide chains in all living organisms known on Earth. Each of these 20 protein amino acids consist of four clusters of atoms branching out from the central carbon atom in three-dimensional space. The amino acids, sugars and many other biomolecules are asymmetric such that chemically identical molecules can exist as mirror image chiral (levororotary $L$ - or dextrorotary $D$-) stereoisomers. Stereoisomers are isomeric molecules that have the same molecular formula but are different only due to the fact that the sequence of their bonded atoms results in different three dimensional orientations of their atoms in space. Enantiomers are two stereoisomers that are related to each other by reflection in that they are mirror images of one another and therefore not superimposable and hence exhibit chirality or "handedness". (The term "chiral" is from the Greek word for "hand".) Glycine is symmetric and therefore does not exhibit chirality. The other 19 amino acids in proteins are all chiral and in living organisms exist solely as the $L$ enantiomer. Furthermore, sugars can also exist as chiral enantiomers. The RNA and DNA molecules of all living organisms use solely the right-handed chiral pentose sugars $D$-ribose (in RNA) or $D$-deoxyribose (in DNA). The homochirality of $L$-amino acids and $D$-sugars is essential for proper folding of proteins and enzymes and for the righthanded helix of the RNA and DNA molecules. Figure 1 shows the configurations of the life-critical amino acid $L$ alanine and sugar $D$-ribose and their associated stereoisomeric forms. 


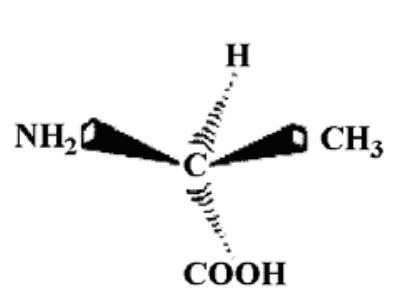

$L$-alanine

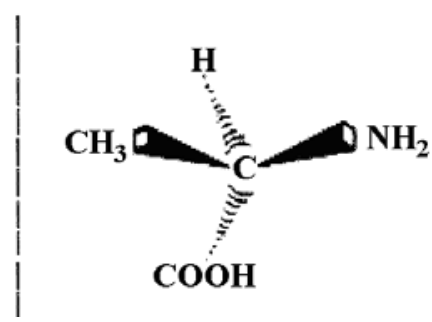

D-alanine

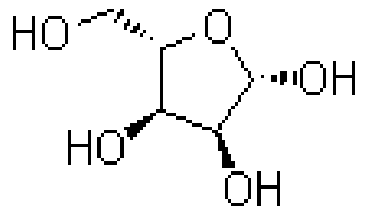

L-ribose

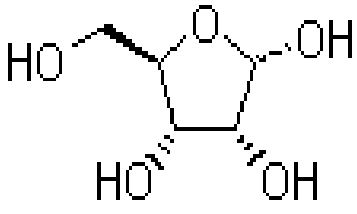

D-ribose

Figure 1. Spatial configuration of stereoisomers of the amino acids $D$ - and $L$-alanine and the pentose sugars $L$ - and $D$-ribose.

It has been known since the Miller-Urey ${ }^{4}$ experiment that amino acids can be produced by abiotic mechanisms. However, just as in the initial experiment, these abiotic processes always result in the formation of racemic mixtures of these molecules in that the two chemically identical enantiomers are produced in essentially equal numbers $(\mathrm{D} / \mathrm{L}=1)$. The origin of homochirality in the molecules of life has remained a great mystery since it was first recognized. Why did Nature choose only $L$-amino acids and $D$-sugars for constructing life-critical biomolecules. Why not the other way around? Why could not life exist that uses exclusively $D$-amino acids and $L$-sugars or only $D$-amino acids and $D$-sugars, etc. The mystery is even greater since there are no known abiotic mechanisms for the production of enantiopure assemblages of these biomolecules even though much research has been carried out and many different abiotic mechanisms have been explored. These include:

1) Linearly polarized light from neutron stars;

2) Mie-scattering of circularly polarized light from faint stars on aligned interstellar dust particles;

3) Circularly polarized light;

4) Magnetochiral effect;

5) Inclusion polymerization in chiral clays;

6) Spontaneous symmetry breaking in crystallization;

7) Vester-Ulbricht hypothesis of parity violation in weak interactions;

8) Action of very high pressure on racemic mixtures;

9) Asymmetric inorganic surfaces (acting as catalysts);

10) Asymmetric autocatalytic reactions;

11) Amplification of chirality by growing polymers and supramolecular assemblies;

12) Amplification of chirality by serine octamers;

13) Yamagata Cumulative Mechanism.

Guijarro and Yus ${ }^{5}$ have recently provided an extensive review of the various theories regarding the origin of the homochirality of the molecules of life. The fundamental problem is that these mechanisms typically result in only a slight increase of one of the two enantiomers and none have been able to yield the enantiopure assemblages of amino acids and other chiral molecules as are encountered in life. Not only is there a problem with the origin of chirality, there is also a problem with the retention of amino acids and chiral of biomolecules after the organism dies. Even if an abiotic process were discovered that could yield enantiopure biomolecular assemblages, there still remains the problem of maintaining them in an enantiopure state over geological time scales.

\subsection{Protein amino acids in modern organisms, fossils and carbonaceous meteorites}

Table 1 shows the protein $L$-amino acids in the exopolysaccharide (EPS) slime sheath of the cyanobacterium Microcystis aeruginosa $\mathrm{K}_{-3 \mathrm{~A}^{6}}$; living cells of the bacteria E. Coli and Salmonella sp. ${ }^{7}$ and ancient terrestrial biology (e.g., a Fly in amber and teeth of a Cretaceous Duck-Billed Hadrosaur ${ }^{8}$ ) for comparison with extraterrestrial amino acids detected in the Murchison, Murray, Orgueil and Ivuna meteorites reported by Ehrenfreund et al. ${ }^{9}$. Engel et al. ${ }^{10,11}$ and Cronin and Pizarello. ${ }^{12}$ The amino acids of Table 1 that are in italics or marked with "-_" or "n.d." were either not detected or present at only trace levels in the fossils in terrestrial rocks and carbonaceous meteorites. Even though there is no doubt that the amber encased fly and the Hadrosaur teeth are biological in origin, it is seen that these fossils are also 
missing several of the same amino acids that absent in the carbonaceous meteorites. Only 8 of the 20 life-critical protein amino acids are detectable in water/acid extracts of carbonaceous meteorites. The fact that several of the amino acids missing in meteorites and ancient terrestrial fossils are relatively abundant in living bacteria provides strong evidence that the meteorites are not contaminated by modern biological materials. If modern contaminants were present, all 20 protein amino acids should be detected.

TABLE I: Amino Acids in Living Bacteria, Fossils and Carbonaceous Meteorites

\begin{tabular}{|c|c|c|c|c|c|c|c|c|c|c|}
\hline \multirow{3}{*}{$\begin{array}{l}\text { Protein Amino Acids } \\
\text { italics - not detected } \\
\text { in meteorites }\end{array}$} & \multicolumn{4}{|c|}{ Living Bacteria $^{6,7}$} & \multicolumn{2}{|c|}{ Fossils $^{8}$} & \multicolumn{4}{|c|}{ Carbonaceous Meteorites ${ }^{9-11}$} \\
\hline & $\begin{array}{c}\text { Microc } \\
\text { ystis }\end{array}$ & $\begin{array}{c}\text { E. } \\
\text { coli }\end{array}$ & $\begin{array}{c}\text { Salm. } \\
\text { pull }\end{array}$ & $\begin{array}{l}\text { Salm. } \\
\text { senf }\end{array}$ & $\begin{array}{c}F y / \\
\text { Amber }\end{array}$ & $\begin{array}{l}\text { Hadr } \\
\text { osaur }\end{array}$ & Murchison & Murray & Orgueil & Ivuna \\
\hline & Wt \% & $\begin{array}{l}\text { Mol/ } \\
\text { ALA }\end{array}$ & $\begin{array}{l}\text { Mol/ } \\
\text { ALA }\end{array}$ & $\begin{array}{l}\text { Mol/ } \\
\text { ALA }\end{array}$ & $\begin{array}{l}\text { Mol/ } \\
\text { GLY }\end{array}$ & $\begin{array}{l}\text { Mol/ } \\
\text { GLY }\end{array}$ & ppb & ppb & ppb & ppb \\
\hline$L$-Alanine ALA & 10.3 & 1.00 & 1.00 & 1.00 & \multirow[t]{2}{*}{0.37} & \multirow[t]{2}{*}{0.53} & 956 & 647 & 69 & 157 \\
\hline D-Alanine ALA & - & - & - & - & & & 720 & 617 & 69 & 82 \\
\hline L-Aspartic Acid ASP & 12.0 & 1.01 & 1.00 & 1.00 & \multirow[t]{2}{*}{0.23} & \multirow[t]{2}{*}{0.77} & 342 & 65 & 54 & 146 \\
\hline D-Aspartic Acid ASP & - & - & - & - & & & 100 & 51 & 28 & 30 \\
\hline$L$-Glutamic Acid GLU & 12.3 & 1.14 & 1.11 & 1.14 & \multirow[t]{2}{*}{0.57} & \multirow[t]{2}{*}{0.67} & 801 & 261 & 61 & 372 \\
\hline D-Glutamic Acid GLU & - & - & - & - & & & 537 & 135 & 15 & 8 \\
\hline Glycine GLY & 8.7 & 0.93 & 1.02 & 0.96 & 1.00 & 1.00 & 2919 & 2110 & 707 & 617 \\
\hline Arginine ARG & 4.4 & 0.51 & 0.48 & 0.52 & - & - & n.d. & n.d. & n.d. & n.d. \\
\hline Histidine HIS & 1.0 & 0.18 & 0.21 & 0.19 & - & - & n.d. & n.d. & n.d. & n.d. \\
\hline Isoleucine ILEU & 5.0 & 0.55 & 0.51 & 0.55 & - & - & - & - & - & - \\
\hline Leucine LEU & 8.2 & 0.83 & 0.78 & 0.78 & - & - & $1.9 \mathrm{Nmol} / \mathrm{g}$ & - & - & - \\
\hline Lysine LYS & 4.4 & 0.56 & 0.59 & 0.56 & - & - & n.d. & n.d. & n.d. & n.d. \\
\hline Methionine MET & 1.9 & 0.31 & 0.37 & 0.23 & - & - & n.d. & n.d. & n.d. & n.d. \\
\hline Phenylalanine PHE & 3.8 & 0.34 & 0.33 & 0.33 & - & - & n.d. & n.d. & n.d. & n.d. \\
\hline Proline PRO & 4.9 & 0.25 & 0.26 & 0.28 & - & - & $13 \mathrm{Nmol} / \mathrm{g}$ & - & - & - \\
\hline Serine SER & 6.6 & 0.41 & 0.48 & 0.43 & 0.56 & 0.91 & $4.7 \mathrm{Nmol} / \mathrm{g}$ & - & - & - \\
\hline Threonine THR & 6.6 & 0.48 & 0.50 & 0.48 & - & 0.41 & n.d. & n.d. & n.d. & n.d. \\
\hline Tryptophan $\mathbf{T R Y}$ & 0.04 & 0.05 & 0.05 & 0.04 & - & - & n.d. & n.d. & n.d. & n.d. \\
\hline Tyrosine TYR & 3.4 & 0.12 & 0.15 & 0.08 & - & - & n.d. & n.d. & n.d. & n.d. \\
\hline Valine VAL & 6.5 & 0.73 & 0.66 & 0.75 & - & 0.24 & - & - & - & - \\
\hline & & & Non-P & $\operatorname{tein} A$ & nino $\mathbf{A}$ & & & & & \\
\hline$\alpha$-Aminoisobutyric AIB & - & - & - & - & - & - & 2,901 & 1,968 & 39 & 46 \\
\hline$\gamma$-Aminobutyric $\gamma$-ABA & - & - & - & - & - & - & 1,331 & 717 & $\sim 600$ & 628 \\
\hline Isovaline $D, L$-IVA & - & - & - & - & - & - & 3,359 & 2,834 & $<194$ & $<163$ \\
\hline
\end{tabular}


With only a few exceptions, all living organisms maintain all of their amino acids as the $L$ - enantiomer and their sugars as the $D$-enantiomer. Ohtani et al. ${ }^{13}$ reported that there is a constant increase with age in the $D$-aspartic acid in the dentin of teeth. Lam et al. ${ }^{14}$ discovered that Vibrio cholerae use a dedicated racemase to produce $D$-Met and $D$-Leu for regulating the synthesis of cell-wall peptidoglycan. After death, many amino acids disappear entirely from the biological remains - decomposing or reacting to form humic-like substances. Also, after the organism dies it loses its ability to employ racemases, epimerases or metabolic pathways to exert control over the chirality of its amino acids. Thus begins the slow process in which the $\mathrm{D} / \mathrm{L}$ ratio moves toward equilibrium in a biogeochemical diagenetic process known as racemization. The racemization rate depends not only on the temperature, humidity, $\mathrm{pH}$, and characteristics of the enclosing matrix, but also on the particular amino acid involved. This process provides the scientific basis for the science of Amino Acid Geochronology. ${ }^{15}$ For example, the amino acid Asparginine quickly becomes racemic and is useful only for dating biological materials from the present back to approximately 25,000 or 30,000 years. On the other hand, Isoleucine racemizes more slowly and is used to date biological materials up to 2 million years in age. According to Bada et al., ${ }^{16}$ the original protein components of biological materials are hydrolyzed to amino acids and then lost to the environment over time scales of $10^{5}-10^{6}$ years. It is important to point out that even though the most abundant amino acids in meteorites (AIB, $\gamma-\mathrm{ABA}$ and IVA) are not included in the twenty protein amino acids they are still related to biology. Isovaline and $\alpha$-aminoisobutyric acid can be formed by diagenetic alterations of ancient biological materials and $\gamma$-Aminobutyric acid can be synthesized by living organisms. Engel and Macko ${ }^{10,11}$ established that there exists a strong enantiomeric excess of $L$-alanine (>50\%) and $L$-glutamic acid (>30\%) in the Murchison meteorite and proved by stable isotopes that these amino acids were both indigenous and extraterrestrial.

\subsection{Missing protein amino acids in terrestrial fossils and carbonaceous meteorites}

The data provided in Table 1 indicates that the most abundant (by weight\%) amino acids in the cyanobacterium Microcystis sp. are GLU, ASP, ALA, GLY and LEU (all above 8\%) followed closely by THR, SER, VAL, ILEU and PRO (all above 5\%). However, GLY is by far the most abundant protein amino acid in the Murchison (CM2), Murray (CM2), Orgueil (CI1) and Ivuna (CI1) carbonaceous meteorites and it is followed by ALA, GLU and ASP. However, in these carbonaceous meteorites, the protein amino acids LEU, THR, SER, VAL, ILEU and PRO are either totally absent or detected only at trace levels. ${ }^{9-12,16-20}$ These results are totally inconsistent with the presence of modern

cyanobacteria or other biological contaminants in these meteorites. Isovaline (IVA), $\alpha$-aminoisobutyric acid (AIB) and $\gamma$-Aminobutyric Acid ( $\gamma$-ABA) are the most abundant non-protein amino acids in carbonaceous meteorites. While they are not protein amino acids it is wrong to conclude that they are not biological in nature. The amino acids IVA and AIB are formed on Earth by the diagenetic alteration of ancient biological materials and $\gamma$-Aminobutyric Acid is synthesized by organisms on Earth. ${ }^{20,21}$ However, most protein amino acids are absent in meteorites and terrestrial fossils and only 8 of the 20 life-critical protein amino acids have been found in carbonaceous meteorites using the most sensitive modern methodologies available.

\subsection{Diagenetic products of chlorophyll in carbonaceous meteorites}

A wide variety of other life-critical biomolecules have been found in carbonaceous meteorites and have been discussed in detail in the volume on Carbonaceous Meteorites by $\mathrm{Nagy}^{22}$ and the recent review by Sephton. ${ }^{23} \mathrm{Kissin}^{24}$ analyzed the organic constituents of five carbonaceous meteorites using infrared spectroscopy and gas chromatographic methods. He confirmed the presence in carbonaceous meteorites of extractable aliphatic components, such as n-alkanes in the range of $\mathrm{C}_{15} \mathrm{H}_{32}$ to $\mathrm{C}_{27} \mathrm{H}_{56}$ and the isoprenoid alkanes (pristane, phytane and norpristane). These isoprenoids are extremely strong biomarkers since they represent the diagenetic breakdown products of chlorophyll. Chlorophyll is the green photosynthetic pigment found in all plants, algae and cyanobacteria. Photosynthetic pigments are vital for all photoautrophic life forms, which comprise much of the basis of the food chain for organotrophs encountered in nature. Furthermore, there are no known abiotic mechanisms for the production of the chlorophyll pigments.

Pristane (2,6,10,14-Tetramethylpentadecane) is a natural saturated terpenoid alkane. Terpenes are polymers of isoprenes $\left(\mathrm{C}_{5} \mathrm{C}_{8}\right)_{\mathrm{n}}$ which are the major building blocks of all life. Pristane is derived from phytol, a common terpenoid found in cyanobacteria ${ }^{25}$ and all plants esterified to chlorophyll. This complex chlorin pigment represents the key to photosynthesis and is consequently a life-critical biomolecule. The chlorophyll $a$ and $b$ molecules consist of a porphyrin ring and a long phytol tail (Fig. 2.a.). Chlorophyll $c$ lacks the phytol chain. The relative concentrations of chlorophylls 
within the cell varies as to type of organism---but chlorophyll $a$ is dominant in the all eukaryotic algae and the prokaryotic "blue green algae" - the cyanobacteria. $\operatorname{Schopf}^{26}$ has reported that both pristine and phytane (presumably derived from chlorophyll) have been detected and represent a biomarker in stromatolitic Proterozoic sediments that contain fossilized remains of cyanobacteria. The head of the chlorophyll molecule is a porphyrin ring with a magnesium atom at its center (Fig. 2.b.). Several enzymes are involved in the complex process of the enzymatic biosynthesis of the tetrapyrroles (e.g., heme and chlorophyll). Louie et al. (1992) ${ }^{27}$ used x-ray analysis to determine the structure of porphobilinogen deaminase (PBGD), which is the enzyme that catalyses the stepwise polymerization of four molecules of its pyrrole substrate. The porphobilinogen then yields the linear tetrapyrrole that is rearranged by subsequent enzymes in the pathway ${ }^{28 .}$

Hodgson and Baker ${ }^{29}$ detected porphyrin metal complexes in samples of the Orgueil, Murray, Cold Bokkeveld, and Mokoia carbonaceous chondrites. They found no evidence of similar pigments in the Vigarano, Indarch, Peace River, and Bruderheim meteorites. The porphyrins present on Earth are the result of complex enzymatically mediated biological processes. However, in 1968, Hodgson and Ponnamperuma ${ }^{30}$ demonstrated prebiotic porphyrin genesis by electric spark discharge in methane, ammonia and water vapor. It is important to note that even though the porphyrin tetrapyrrole complexes, which are the diagenetic products of chlorophyll, have been detected in carbonaceous meteorites, the diverse chlorophyll pigments themselves have never been found in carbonaceous meteorites. The biosynthesis and diagenetic pathways related to the photosynthetic biomolecules are very complex. Furthermore, diagenetic alteration of the pigments is a slow biogeochemical process that begins by action of anaerobic purple sulfur bacteria, which play a crucial initial role in the pigment diagenesis, which proceeds via a series of complex diagenetic steps for the transition from the phorbides to the poryphyrins. ${ }^{31,32}$ If the cyanobacterial filaments in the carbonaceous meteorites were modern bio-contaminants, then the pigments themselves would be detected rather than their diagenetic breakdown products.

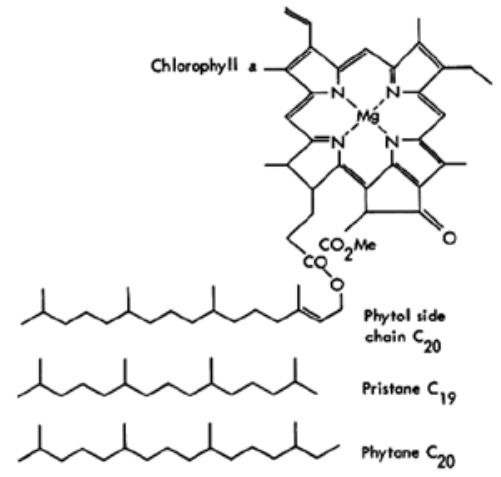

a.

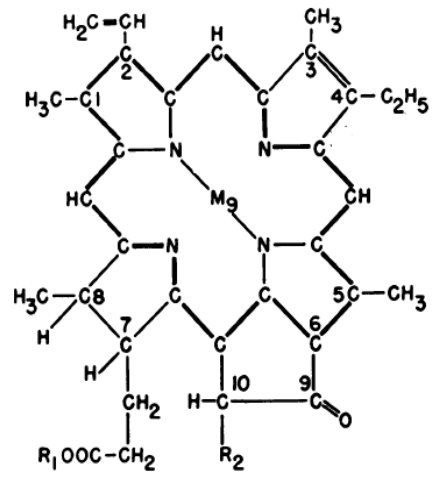

b.

Figure 2. Chlorophyll $a$ showing a. the long Phytol $\left(\mathrm{C}_{20}\right)$ side chain with the structural configurations of Pristane $\left(\mathrm{C}_{19}\right)$ and Phytane $\left(\mathrm{C}_{20}\right)$ "tails" and $\mathbf{b}$. detail of the magnesium porphyrin ring of the "head" of the chlorophyll $a$ molecule.

\subsection{Nitrogen heterocycles of nucleic acids: Purines and pyrimidines in life and carbonaceous meteorites}

Purines and pyrimidines are the nitrogen heterocycle bases of the nucleotides, which are joined together to form the structural units of the deoxynucleic acid (DNA) and ribonucleic acid (RNA) biomolecules. Nucleotides play a crucial role in the information storage, protein synthesis, and metabolism. They are absolutely essential to all life on Earth and therefore their components must be considered to constitute extremely strong chemical biomarkers. Each nucleotide is comprised of a nitrogen heterocycle nucleobase, a 5-carbon pentose sugar (with the carbons designated 1' to 5') and one to three phosphate groups. The chiral sugars (ribose in RNA or 2'-deoxyribose in DNA) are all the Denantiomers to insure proper coiling of the helix. Nucleotides can contain either a purine or a pyrimidine base. The purines (adenine and guanine) have a structure with two rings and the pyrimidines (cytosine, thymine and uracil) have only one ring (Fig. 3). The strands of DNA are polymers of repeating units of these nucleotides. The crucial property of the DNA molecule is the formation of dimers via the strong hydrogen bonds linking pairs of one purine and one pyrimidine (e.g., the guanine-cytosine or the adenine-thymine bonded pairs) into the anti-parallel strands of the twin helix. Adenine, cytosine and guanine are found in both RNA and DNA. Thymine is only present in DNA and uracil is found only in RNA. 
In 1960, Calvin and Vaughn ${ }^{33}$ first reported the detection of the purine and pyrimidine nucleobases in carbonaceous meteorites and considered the implications of this finding to biological evolution and the possible existence of extraterrestrial life. In 1964, Hyatsu ${ }^{34}$ used paper chromatography to detect the purines (adenine and guanine) and possibly the pyrimidine (Uracil) in the Orgueil CI1 carbonaceous meteorite. He also reported detecting compounds with the sym-triazine ring structures (melamine and ammeline) in Orgueil. At the time it was thought that these compounds had no possible relationship to biology. However, in 2010 Seffernick et al. $^{35}$ described the metabolic pathways that use the guanine deaminase enzyme to allow ammeline to act as an intermediate in the bacterial metabolism of melamine.) Hyatsu et al. ${ }^{36}$ presented a detailed review of nitrogen compounds in carbonaceous meteorites. Guanylurea and the the purine adenine were conclusively identified Orgueil but they failed to detect the purine guanine and the pyrimidines cytosine and thymine. The detection of these nitrogen heterocycles of nucleobases was so astonishing that they were considered either evidence for extraterrestrial life or of some previously unknown abiotic process. Modern biological contamination was not a logical explanation due to absence of the pyrimidines cytosine and thymine. These are essential in the DNA of all organisms and they have never been detected in any of the carbonaceous meteorites studied.

Extensive studies were undertaken to search for nitrogen heterocyclic compounds and amino acids in the pristine stones of the Murchison CM2 carbonaceous meteorite. Many of these stones were collected immediately after the meteorite was observed to fall at 10:59 A. M. on Sept 18, 1969 in Murchison, Australia. Some were picked up by eyewitnesses while the fusion crust was still hot. Many were found the next day and collected by students of Prof. John Lovering. ${ }^{37}$ Folsomme et al. ${ }^{38}$ and Hyatsu et al. ${ }^{39}$ detected indigenous nitrogen heterocycles in Murchison. Stoks and Schwartz ${ }^{40}$ confirmed these findings and expanded them by the detection (at concentrations ranging from 114-655 ppb) of the purines (adenine, guanine, hypoxanthine and xanthine) (Fig. 3) in formic acid extracts of alls sample they studied of the CI1 (Orgueil) and CM2 (Murchison and Murray) meteorites. Their analysis for nitrogen-heterocyclic compounds in meteorites used gas chromatography, cation and anion exclusion liquid chromatography, and mass spectrometry.

\section{Purines}<smiles>Nc1ncnc2[nH]cnc12</smiles>

Adenine<smiles>Nc1nc2[nH]cnc2c(=O)[nH]1</smiles>

Guanine<smiles>O=c1[nH]cnc2[nH]cnc12</smiles>

Hypoxanthine<smiles>O=c1[nH]c(=O)c2nc[nH]c2[nH]1</smiles>

Xanthine

\section{Pyrimidine}<smiles>O=c1cc[nH]c(=O)[nH]1</smiles>

a.

\section{Pyrimidines Not Found in Carbonaceous Meteorites}
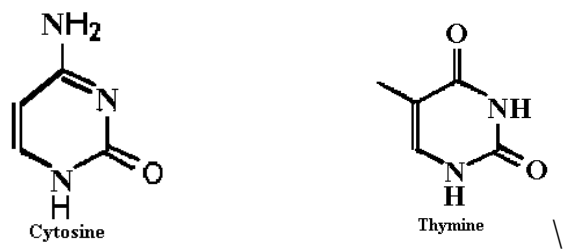

b.

Figure 3. Life-critical nitrogen heterocyclic bases of nucleic acids include perinea and the pyrimidine a.) Present in carbonaceous meteorites and b.) missing RNA and DNA pyrimidines (cytosine and thymine) that have never been detected in meteorites.

Xanthine and Hypoxanthine are not components of either RNA or DNA, but they are important intermediates in the synthesis and degradation of purine nucleotides. The pyrimidine uracil was also detected in Murchison. ${ }^{41,42}$ The significance, possible formation mechanisms and implications of the purines and pyrimidines found in the carbonaceous meteorites were considered in detail ${ }^{41,42}$ There exists an incredibly high molecular diversity of extraterrestrial organic 
matter and chemical biomarkers in the Murchison CM2 meteorite. In 2010, Schmitt-Kopplin et al. ${ }^{43}$ reported the identification of 46,696 distinct chemical compounds using Fourier-Transform Ion Cyclotron Resonance/Mass Spectrometry study of the Insoluble Organic Matter (IOM - $\mathrm{C}_{100} \mathrm{H}_{70} \mathrm{~N}_{3} \mathrm{O}_{12} \mathrm{~S}_{2}$ ) in Murchison

In 2008, Martins ${ }^{44}$ described the results of their compound-specific carbon isotopic measurements of nucleobases extracted from the interior of a Murchison fragment. The $\delta^{13} \mathrm{C}$ values obtained was $+44.5 \%$ o for the pyrimidine Uracil and $+37.7 \%$ or the purine Xanthine thereby providing undeniable proof that these nucleobases are both indigenous to the meteorite and extraterrestrial in nature. It has been confirmed by independent studies that the purines (Adenine, Guanine, Xanthine and Hypoxanthine) and the pyrimidine (Uracil) are indigenous and that other life-critical components of DNA and RNA (Cytosine and Thymine) are not detectable in these meteorites. The missing life-critical nitrogen heterocyclic compounds, combined with the missing sugars and protein amino acids provide convincing evidence that these stones are not contaminated by modern cyanobacteria or other microorganisms. If the meteorites were contaminated by living or recently dead organisms or pollen, then all of the purines and pyrimidines essential for the DNA and RNA molecules would certainly be present. However, it should be pointed out that cytosine and thymine are unstable. Their absence in these stones does not in any way imply that biology was not responsible for the purines and pyrimidines that have been found in the meteorites. Ultraviolet radiation of cellular DNA rapidly results in denaturation and the formation of a variety of pyrimidine photoproducts. Ganguly and Duker ${ }^{44}$ showed that thymine hydrates are produced by high fluxes of UV radiation on DNA and that the half-life of thymine hydrates is only 33.3 hours. Furthermore, Levy and Miller ${ }^{44}$ have shown that at $0{ }^{\circ} \mathrm{C}$ and $\mathrm{pH}$ 7, guanine decomposes to xanthine (half-life 1.7 million years) and cytosine decomposes to uracil (half life $\sim 17,000$ years).

\subsection{Missing Nitrogen in Filamentous Microfossils in carbonaceous Meteorites}

Nitrogen is present in the amino acids and nucleic acid bases of all life forms on Earth. The nitrogen content of all living cells typically ranges from $\sim 2 \%$ to $18 \%$ (atomic). The fixed nitrogen in the proteins, nucleic acids and other biomolecules of organisms is very slowly lost after death of the organism. The fixed nitrogen is broken up and slowly returned to the gaseous di-nitrogen $\left(\mathrm{N}_{2}\right)$ component of Earth's atmosphere. These microbial and diagenetic processes are part of the biogeochemical "nitrogen cycle". However, FESEM and EDS studies carried out at NASA/MSFC have shown that the nitrogen is lost from organisms over time scales hundreds of thousands to millions of years (rather than hundreds or thousands of years). The EDS studies have repeatedly shown that nitrogen is not detectable in the filaments in carbonaceous meteorites. The missing nitrogen in the filaments provides a valuable bio-discriminator. The nitrogen content of the meteorite filaments is consistent with that of ancient biological remains rather than modern terrestrial biological contaminants.

Field Emisssion Scanning Electron Microscopy (FESEM) studies have been carried out on freshly fractured interior surfaces of a wide variety of carbonaceous chondrites, stony and enstatite chondrites, diogenites and iron meteorites. The carbonaceous meteorites with names Boldface have been found to contain filamentous microstructures interpreted as the indigenous remains of microfossils of cyanobacteria or other trichomic prokaryotes. Filamentous microfossils have never been observed in the meteorites whose names are in italics.

\section{Carbonaceous Chondrites Investigated at NASA/MSFC}

(Boldface: Filaments Observed; Italics: Filaments Not Detected)

CI1 Ivuna Group, Type 1: Alais (France) Fall, March 15, 1806; Orgueil (France) Fall, May 14, 1864; Ivuna (Tanzania) Fall Dec. 16, 1938

C2 Ungrouped: Tagish Lake (British Columbia) Fall, January 18, 2000

CM2 Mighei Group, Type 2: Cold Bokkeveld, Fall, (South Africa) October 13, 1838; Nogoya, Fall, (Argentina) June 30, 1879; Mighei, (Ukraine) Fall, June 18, 1889; Murray, (Kentucky) Fall, September 20, 1950; Bells, Fall (Texas)

September 9, 1961; Murchison (Australia) Fall, September 18, 1969

CR3: Renazzo Group, Type 3: Acfer 324; Find, (Algeria), 2001

CK4: Karoonda Group, Type 4: Karoonda; Fall, (Australia) November 25, 1930

CO3: Ornans Group, Type 3: Rainbow, Find, (Australia( 1994; Dar al Gani (DaG) 749, Find (Libya) 1999; Kainsaz; Fall (Russia) September 13, 1937

CV3: Vigarano Group, Type 3, Efremovka, Find (Kazakhstan) July, 1962; Allende, Fall (Mexico) 2/8/1969 


\section{Stony and Enstatite Chondrites, Diogenites and Iron Meteorites Investigated at NASA/MSFC}

Iron: IIIAB Medium Octahedrite: Henbury; Find (Australia) 1931

Acapulcoite: Til 99002; Find (Thiel Mountains, Antarctica) 2000 (Antarctica 2000 Expedition)

Ordinary Chondrite H-5: Til 99003; Til 99010; Til 99015; Finds (Thiel Mountains, Antarctica)

L-4: Barratta; Find, (Australia) 1845; Nikolskoye (Russia) Fall, March 6, 1954; Til 99001; Til 99004; Til 99007; Til 99012; Til 99013; Til 99017; Finds (Thiel Mountains, Antarctica), January, 2000 (Antarctica 2000 Expedition)

L-6: L6: Holbrook (Arizona) Fall, 1912

Enstatite Chondrite EL6: Til 99016; Find (Thiel Mountains, Antarctica) 2000

Achondritic Diogenite ADIO: Tatahouhine (Tunisia) Fall, June 27, 1931

Figure 4 provides examples of images and EDS data on filaments in the Orgueil CI1 and Murchison CM2 meteorites.

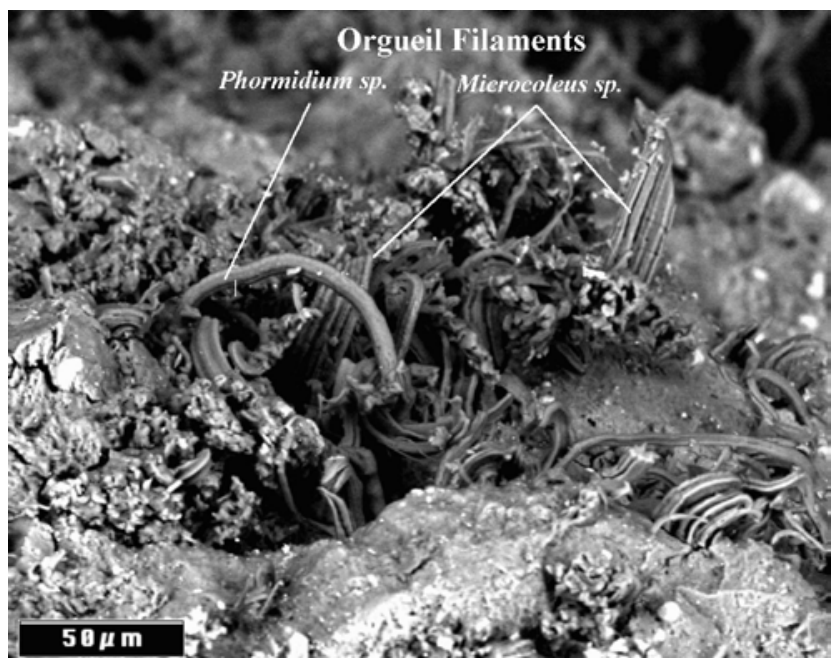

a.

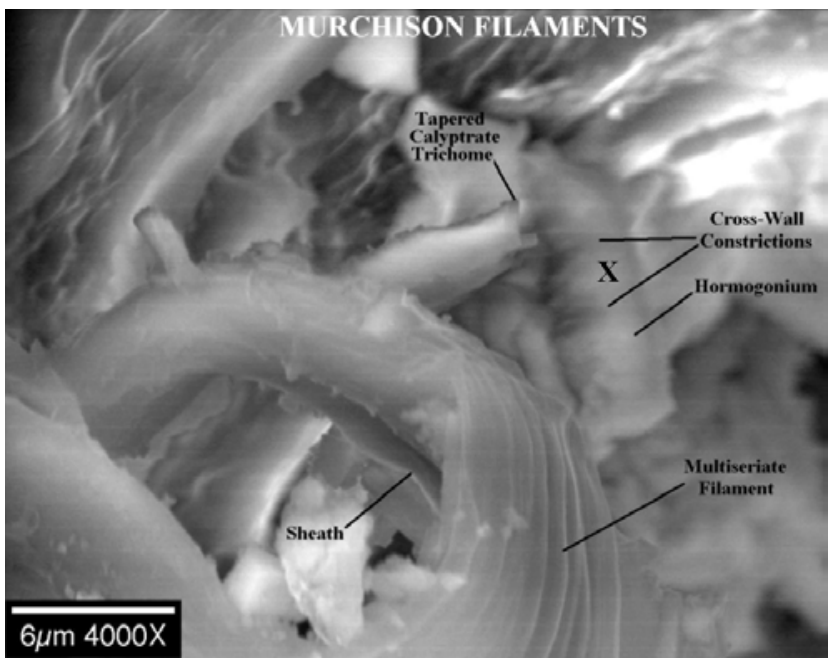

C.

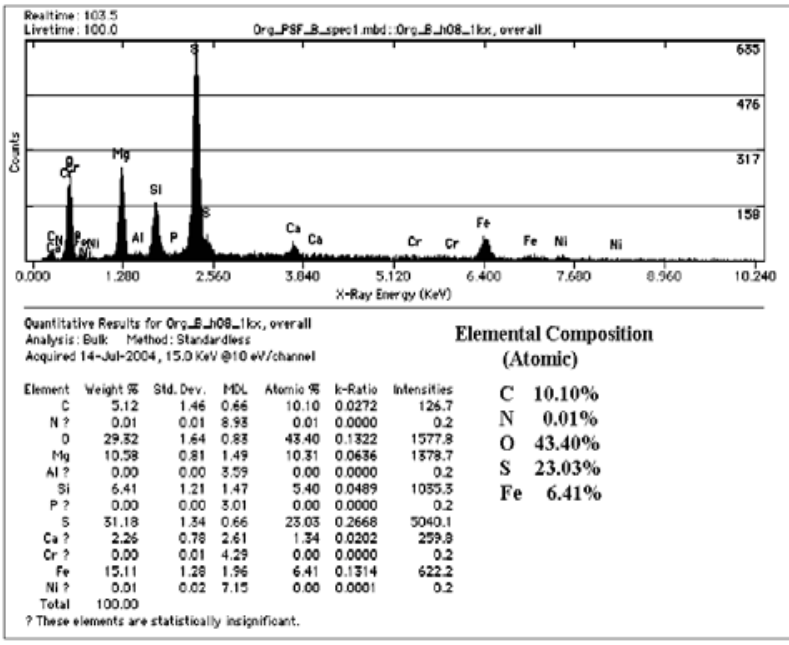

b.

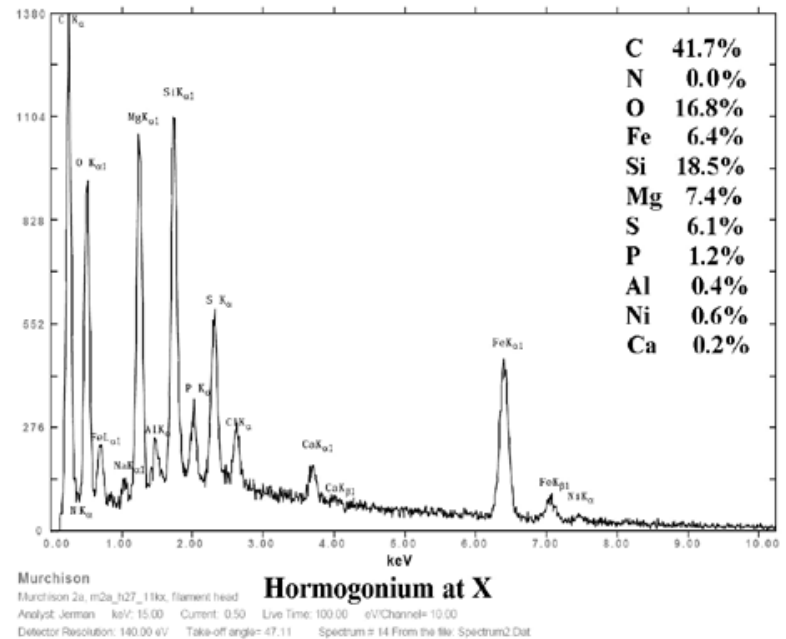

d.

Figure 4. Filamentous microfossils in carbonaceous meteorites. a. FESEM image of mat of uniseriate (cf. Phormidium sp.) and multiseriate (cf. Microcoleus sp.) filaments in Orgueil CI1 meteorite with b. EDS data of overall field showing Nitrogen at trace levels; c. Murchison tapered uniseriate filament with calyptrate apical cell and multiseriate filaments (cf. Microcoleus sp.) with delaminated sheath and hormogonium with cross-wall constrictions and $\mathbf{d}$. elemental composition at spot $\mathbf{X}$ showing missing nitrogen. 
Figure 5 provides examples of images and EDS data of herbarium diatoms and cyanobacterial filaments in Vostok ice.
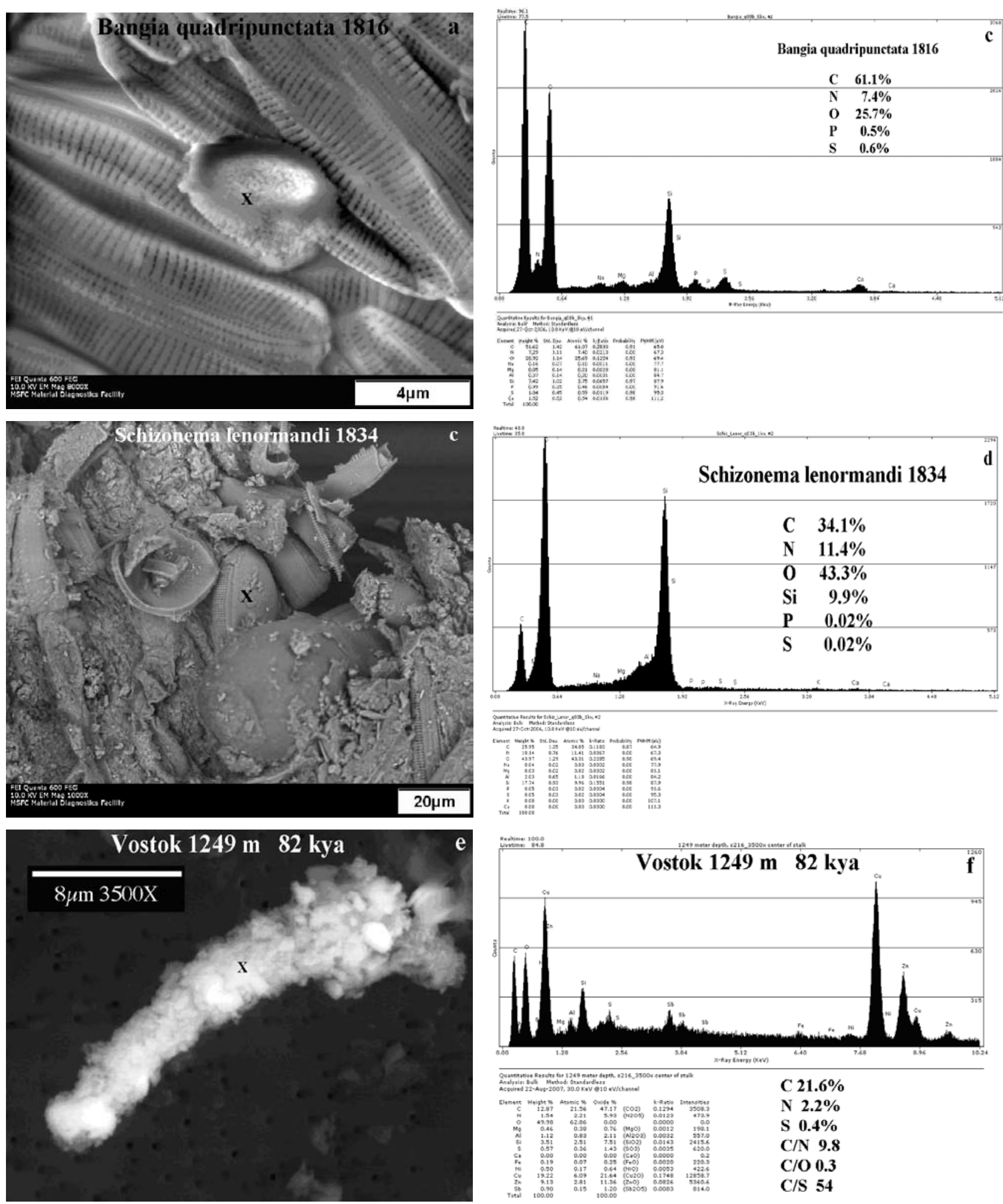

Figure 5. FESEM images of and EDS spectra taken at spots marked by the $\mathbf{X}$ for diatoms collected (a, b) in 1816 and (c, d) in 1834 and for a cyanobacterial filament (Limnothrix sp.) from 82,000 year old ice from Vostok, Antarctica. 
Figure 4.a. is a Field Emission Scanning Electron Microscope (FESEM) image of a dense cyanobacterial mat in the Orgueil CI1 carbonaceous meteorite. The components of this complex mat of filaments are consistent in size and morphology with those encountered in terrestrial prokaryotic mats of Oscillatoriales cyanobacteria. They are often found in association with trichomic filamentous sulfur bacteria. These cyanobacterial mats are found all over the world and frequently include the cosmopolitan genera and species of multiseriate cyanobacteria (cf. Microcoleus chthonoplastes.). This species is often found in alkaliphilic and hypersaline communities ${ }^{47}$ and in the polar regions of Earth in association with the uniseriate Oscillatoriales (cf. Phormidium spp., Lyngbya spp. or Leptolyngbya spp.) in mats. The filaments seen in this mat assemblage in the meteorite are consistent in size and morphology with species of Microcoleus, Phormidium and Lyngbya. Figure 4.b. is the Energy Dispersive X-ray Spectroscopy (EDS) data for the overall region shown in the image. Thick red stromatolitic mats, composed with a dominant component of Phormidium autumnale were found on the floor of Lake Untersee, Antarctica during the Tawani 2008 International Schirmacher Oasis/Lake Untersee Expedition in East Antarctica. ${ }^{48}$ The cyanobacterial components of the Phormidium, Lyngbya and Leptolyngbya mats express the nifH enzyme which makes it possible for them to perform dark-period nitrogen fixation. ${ }^{49}$ The ability to perform dark-period nitrogen fixation would be of profound value for life forms that grow deep beneath thick layers of ice in perennially ice-covered Antarctic lakes. This ability to inhabit such environments would be of great value for life that might grow in liquid water beneath the thick crust of a comet, where high levels of sunlight are only periodically available and then for very short periods of time. Figure 4.c. is an FESEM image of filaments in the Murchison CM2 carbonaceous meteorite. In this single $(\sim 20 \mu \mathrm{X} 30 \mu)$ field of view, it is possible to see several different and clearly recognizable cyanobacterial filaments including a tapered uniseriate filament with a calyptrate apical cell; a multiseriate filament similar to Microcoleus chthonoplastes with a delaminated sheath and an escaped hormogonium with cross-wall constrictions delineating 3 internal spherical cells of $\sim 2.8 \mu$ diameter and $\mathbf{d}$. elemental composition of the hormogonium at spot $\mathbf{X}$ showing missing nitrogen and relatively high content of carbon, sulfur and iron.

\subsection{Nitrogen in Modern and Ancient Filamentous Diatoms and Cyanobacteria}

Nitrogen is not detectable or present in only trace levels (typically $0.01 \%$ to $0.2 \%$ ) in the recognizable biological remains of filaments detected in the carbonaceous meteorites that landed in 1806 (Alais CI1); 1864 (Orgueil CI1); and 1969 (Murchison CM2). However, nitrogen in living biological materials typically ranges from 2 to $18 \%$, with low values being detected in thick cyanobacterial sheaths and woody tissues of plants and high values detected in protein rich rapidly dividing cells, hair, etc. The missing nitrogen in the microfossils found in the carbonaceous meteorites led to a study of Holocene and Pleistocene biological materials from different environmental conditions and Proterozoic and Archaean terrestrial fossils to evaluate how rapidly nitrogen is removed after death of the organism.

Figure 5 shows FESEM images (5.a, 5.c and 5.e) and EDS elemental data (5.b, 5.d, and 5.f) obtained at the spot marked $\mathbf{X}$ for diatoms and cyanobacteria. The samples are of type specimens of diatoms from the Albert Grunow Herbarium collection of the Henri van Heurck Museum in Antwerp, Belgium. The diatoms included are filamentous algae that grow encased in thick exopolysaccharide (EPS) sheaths. They had been maintained in dry conditions at room temperature and in the dark between herbarium sheets since they were collected by Hoffman Bang in 1816 (Bangia quadripunctata,Lyngbye 1819) ${ }^{50}$ and by Lenormand in 1834 (Schizonema lenormandi, Kützing 1844). ${ }^{51}$ The museum storage conditions experienced by these samples were comparable to those for by the Alais CI1 (1806) and the Orgueil CI1 (1864) carbonaceous meteorites. The nitrogen content in the diatom filaments (7.4\% and $11.4 \%)$ is within the range of that found for living organisms even though they were collected in the early 1800's, This is not surprising since Hoover (1979), ${ }^{52}$ while conducting the inventory of the Albert Grunow Herbarium in Antwerp fractured one of these filaments, put it on a microscope slide and added distilled water. Many diatoms emerged from their sheaths and began swimming with distinctive motility characteristic of pennate diatoms. These diatoms were still alive, after storage in dry state for $\sim 150$ years. The tapered trichomic cyanobacterial filament (Limnothrix sp.) has 2.2\% nitrogen. It was extracted from the $1249 \mathrm{~m}$ depth Vostok ice core collected and provided by Sabit Abyzov of the Institute of Microbiology in Moscow. Ruddiman et al. ${ }^{53}$ presented a methane-based time scale for Vostok ice indicating the age of the $1249 \mathrm{~m}$ depth ice core is $\sim 82,000$ years. Figure 6 is a compilation of EDS Nitrogen data for filaments, trichomes, sheaths, heterocysts, akinetes, and hormogonia in the Orgueil CI1 (1-27); Ivuna CI1 (28) and Murchison (29) meteorites. EDS nitrogen data are compared with a recent contaminant of fungi from Murchison fusion crust (30,31); living cyanobacterial filaments (32-43) and microbial extremophiles ${ }^{54,55}$ Spirochaeta americana (44) and Carnobacterium pleistocenium (48); diatoms Bangia quadripunctata (45,46); hair from a 5 kya Egyptian mummy (49) and 15 kya Siberian Mammoth (49,50) Limnothrix sp. in 1249m 82 kya Vostok ice core; Cambrian trilobite Peronopsis interstrictus (52,53) and 2.7 Gya cyanobacterial filament from the Archaean tufagenic-sedimentary rocks of the Khizovaar green-belt of Karelia, Russia. 


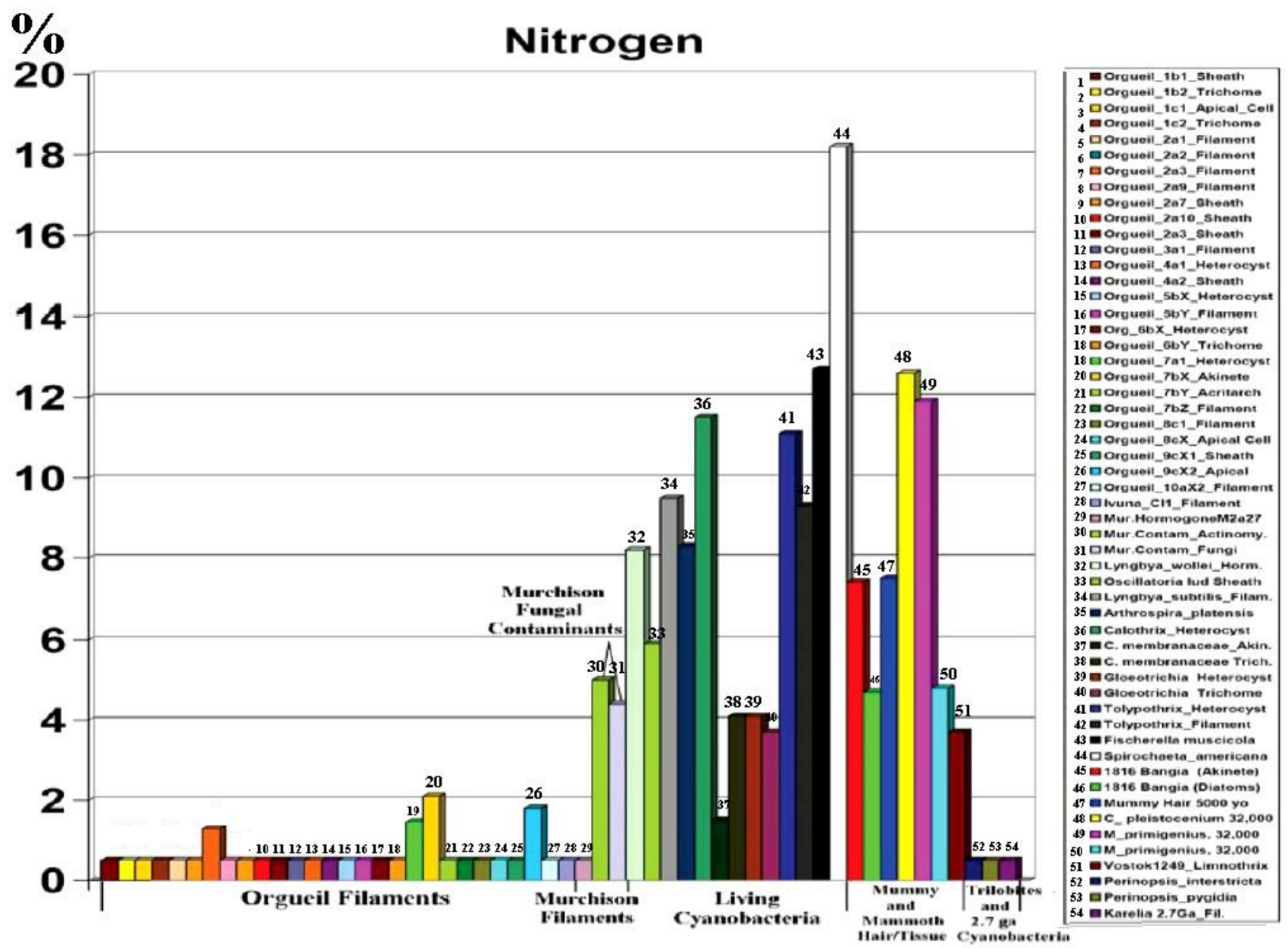

Figure 6. EDS data on nitrogen content of filaments, trichomes, sheaths, heterocysts, akinetes. and hormogonia in the Orgueil, Ivuna and Murchison carbonaceous meteorites compared with the nitrogen values measured for living extremophiles and cyanobacteria, hair and tissue from a 5000 year old mummy, Pleistocene mammoth, Cambrian trilobite and 2.7 Gya cyanobacterial filament from Karelia..

It is seen Figure 6 that the nitrogen levels of filaments and hormogonia in the CI1 and CM2 meteorites (1-29) are similar to the nitrogen levels of the middle Cambrian (505 Mya) trilobite Peronopsis interstrictus (52,53) from the Wheeler Shale of Utah and the 2.7 Gya cyanobacterial filament (54) from Karelia, Russia. However, the nitrogen of the meteorite filaments are very different from the nitrogen levels found in living cyanobacterial filaments, heterocysts, akinetes, hormogonia, and fungal contaminants (30-44) and Holocene and Pleistocene hair and tissue (45-51). The missing nitrogen in the meteorite filaments and presence of nitrogen in Holocene and Pleistocene biology establishes that these filaments can not be modern terrestrial biological contaminants that entered the stones after they arrived on Earth.

\section{CONCLUSIONS}

Independent studies have established that carbonaceous meteorites contain only 12 of the 20 protein amino acids. Several of these exhibit a moderate to strong excess of the $L$-enantiomer and stable isotope data $\left(\delta^{13} \mathrm{C}\right)$ established that they indigenous and extraterrestrial. No mechanisms are known to explain the enantiomeric excess observed. However, the missing protein amino acids and nitrogen supports the hypothesis that they resulted from ancient biological processes on the meteorite parent body followed by destruction and alteration of unstable amino acid and partial racemization of the more stable ones that remain. Extensive evidence indicates that carbonaceous meteorites contain strong chemical biomarkers: protein amino acids; nitrogen heterocycles of nucleic acids; pristine and phytane of chlorophyll pigments 
and well preserved microfossils that are morphotypes of known genera and species of cyanobacteria. EDS data shows nitrogen is typically below detectability $(<0.5 \%)$ in meteorite filaments, Cambrian Trilobites and Archaean cyanobacteria but present at 2-18\% in living bacteria and cyanobacteria and Holocene and Pleistocene hair and tissue. The absence of nitrogen in the filaments combined with the absence of sugars, twelve protein amino acids, and two nucleobases provide clear and convincing evidence that the cyanobacterial filaments detected in the meteorites are not modern biological contaminants. They are therefore interpreted as the indigenous remains of filamentous trichomic cyanobacteria that grew on the parent bodies (probably comets) of the carbonaceous meteorites. ${ }^{56}$

Biogenicity: The presence in the CI1 and CM2 carbonaceous meteorites of recognizable microfossils and the moderate to strong enantiomeric excess of extraterrestrial protein amino acids along with a host of other strong biomarkers provides clear and convincing evidence for biological activity. The $L$-enantiomeric excess of protein amino acids in carbonaceous meteorites is not consistent with any known abiotic production mechanisms. Living organisms routinely produce enantiopure assemblages of chiral biomolecules but there are no known abiotic processes that yield the enantiomeric excess of chiral amino acids and amines that are present in the Murchison and Orgueil carbonaceous meteorites. The fact that the meteorite amino acids and nucleobases are extraterrestrial has been confirmed by stable isotope data. On Earth, the D/L ratio of chiral biomolecules approaches 1 (a racemic mixture) over a time scale of millions (rather than hundreds) of years and no abiotic processes known produce the enantiomeric excess of the chiral biomarkers in the meteorites. The enantiomeric excess of chiral amino acids in carbonaceous meteorites can be explained by biological activity on the parent body followed by subsequent racemization and loss of unstable amino acid. There are no known abiotic mechanisms that could yield the observed assemblage of chiral biomarkers.

Indigenicity: The presence in the CI1 and CM2 carbonaceous meteorites of only 8 of the 20 protein amino acids; only 3 of the 5 life critical nucleobases and the presence of sugar alcohols but the absence of sugars conclusively rules out the possibility that the modern biological contamination of the meteorites. If the carbonaceous meteorites were contaminated with recent cyanobacteria, bacteria, fungi or pollen then all 20 of the protein amino acids would be easily detected using the extremely sensitive analysis techniques now used.

The presence in carbonaceous meteorites of only 3 of the 5 nucleobases of DNA and RNA and only 8 of the 20 protein amino acids combined with the absence of nitrogen in the filaments establishes that the permineralized morphotypes of filamentous cyanobacteria found embedded in the meteorite matrix can not possibly represent modern biological contaminants and therefore must be interpreted as indigenous microfossils of extraterrestrial life forms.

\section{ACKNOWLEDGEMENTS}

I want to thank Gregory Jerman and James Coston of the NASA Marshall Space Flight Center for FESEM and EDS analysis support and Dr. William Birch, Victoria Museum, Melbourne for Murchison samples; and Dr. Paul Sipiera, PSF and Dr. Claude Perron, Musée Nationale d'Histoire (Paris) for Orgueil samples. I also thank Academician Alexei Yu. Rozanov (RAS), Acedemician Erik Galimov of Vernadsky Institute, (RAS), Prof. John F. Lovering and Dr. Rosemarie Rippka of Pasteur Institute for helpful discussions.

\section{REFERENCES}

[1] Arago, D. F. K. "Memoire sur une modification remarquable qu'eprouvent les rayons lumineux dans leur passage a travers certains corps diaphenes, et sur quelques autres nouveaux phenomenes d'optique.” Mem. Inst. Fr. 1, 93134 (1811).

[2] Biot, J. -B, Mem. Cl. Sci. Math. Phys. Inst. Imp. Fr. 1, 1-371 (1814).

[3] Flack, H. D., "Louis Pasteur's discovery of molecular chirality and spontaneous resolution in 1848, together with a complete review of his crystallographic and chemical work.” Acta Crystallographica Sec.A. Foundations of Crystallography, A65, 371-389 (2009). http://crystal.flack.ch/sh5092.pdf

[4] Miller, S. L., H. C. Urey, "Organic Compound Synthesis on the Primitive Earth." Science 130, 245-251 (1959).

[5] Guijarro, A. and M. Yus "Origin of Chirality in the Molecules of Life." http://www.rsc.org/publishing/ebooks/2008/9780854041565.asp (2008)

[6] Nakagawa, M., Takamura, Y. and O. Yagi, "Isolation and characterization of the Slime from a Cyanobacterium, Microcystis aeruginosa K-3A.” Agric. Biol. Chem. 51, 329-387 (1987). 
[7] Howe, J. M., Featherston, W. R., Stadelman, W. J. and G. H. Banwart. “Amino Acid Composition of Certain Bacterial Cell-Wall Proteins.” Appl. Microbiol. 13, 650-652 (1965).

[8] Ostrum, P. H., Macko, S. A., Engel, M. H., Silfer, J. A. and D. Russell. "Geochemical characterization of high molecular weight material isolated from Late Cretaceous fossils.” Adv. Org, Chem. 16, 1138-1144 (1990).

[9] Ehrenfreund, P., Glavin, D. P., Botta, O., Cooper, G. and J. Bada. "Extraterrestrial amino acids in Orgueil and Ivuna: Tracing the parent body of CI type carbonaceous chondrites.” PNAS 98, 2138-2141 (2001).

[10] Engel, M. H., Macko, S. A. and J. A. Silfer. "Carbon isotope concentration of individual amino acids in the Murchison meteorite.” Nature 296, 47-49 (1990).

[11] Engel, M. H., and S. A. Macko. "The stereochemistry of amino acids in the Murchison meteorite.” Precambrian Research, 106, 35-45 (2001).

[12] Cronin, J. R. and S. Pizarello. “Enantiomeric Excesses in Meteoritic Amino Acids.” Science 14, 951-957 (1997).

[13] Ohtani, S., Yamada, Y., Yamamoto, I., Marumo, T., Sugeno, H., Sugimoto, H. Ogasawara, A. and M. Yamagishi. "Estimation of the age of teeth using the racemization of aspartic acid (Racemization Method)." Nihon Hoigaku Zasshi, http://www.ncbi.nlm.nih.gov/pubmed/11060990, (In Japanese). 54, 207-218 (2000).

[14] Lam, H., Oh, D. C., Cava, F., Takacs, C. N., Clardy, J., de Pedro, M. A. and M. K. Waldor. "D-Amino Acids Govern Stationary Phase Cell Wall Remodeling in Bacteria.” Science 325, 1552-1555 (2009).

[15] http://www.geo.umass.edu/amino/aalhome.html

[16] Bada, J. L., Wang, X. S. and H, Hamilton. "Preservation of Key Biomolecules in the Fossil Record: Current Knowledge and Future Challenges.” Phil. Trans. Roy. Soc. Lond. 354, 77-87 (1999).

[17] Kvenvolden, K., Lawless, J., Pering, K., Peterson, E., Flores, J., Ponnamperuma, C., Kaplan, I. R. and C. Moore. "Evidence for Extraterrestrial Amino-acids and Hydrocarbons in the Murchison Meteorite," Nature 228, 923-926 (1970).

[18] Engel, M. E.,and B. Nagy. "Distribution and enantiomeric composition of amino acids in the Murchison meteorite.” Nature 296, 837-840 (1982).

[19] Engel, M. E., Andrus, V. E. and S. A. Macko. “Amino Acids as Probes for Life’s Origin in the Solar System.” in Perspectives in Astrobiology, Vol. 366, NATO Science Series: Life and Behavioural Sciences (R. B. Hoover, R. Paepe, and A. Yu. Rozanov, Eds.) IOS Press, Amsterdam, The Netherlands, pp. 25-37 (2005).

[20] Engel, M. H. and S. A. Macko “The Significance of Protein Amino Acids in Carbonaceous Meteorites.” Geological Society of America Abstracts with Programs, Vol. 35, No. 6, p. 275 (2003).

[21] Mita H. and Shimoyama, A. " $\alpha$-Aminoisobutyric Acid and Isovaline in Tokyo Bay Sediments-Structure of new peptaibols, trichokidins I-VII from fungus Trichoderanum harzianum.” Geochim. Cosmochim. Acta, 62, 47-50 (1998).

[22] B. Nagy, Carbonaceous Meteorites, Elsevier Scientific Publishing Co., New York, pp. 1-747 (1975).

[23] Sephton, Mark A. “Organic Matter in Carbonaceous Meteorites: Past Present \& Future Research.” Phil. Trans. Roy. Soc. A, 363, 2229-2742 (2005).

[24] Kissin, Y. V. "Hydrocarbon components in carbonaceous meteorites.” Geochim Cosmochim. Acta 67, 1723-1735 (2003).

[25] Proteau, P. L. "Biosynthesis of Phytol in the Cyanobacterium Synechocystis sp. UTEX 2470: Utilization of the Non-Mevalonate Pathway.” J. Nat. Prod. 61, 841-843 (1998).

[26] Schopf, J. W., C. Klein, The Proterozoic Biosphere: A Multidisciplinary Study, Cambridge Univ. Press, 597 (1992).

[27] Louie, G.V., Brownlie, P. D., Lambert, R., Cooper, J. B., Blundell, T. L., Wood, S. P., Warren, M. J., Woodcock, S. C. and P. M. Jordan. "The three dimensional structure of porphobilinogen deaminase: a flexible multidomain polymerase with one catalytic site.” Nature 359, 33-39 (1992).

[28] http://www.cryst.bbk.ac.uk/recent_structures/pbgd/pbgd.html

[29] Hodgson, G. W. and B. L. Baker. "Porphyrins in meteorites: Metal complexes in Orgueil, Murray, Cold Bokkeveld, and Mokoia carbonaceous chondrites.” Geochim. Cosmochim. Acta 33, 943-958 (1969).

[30] Hodgson, G. W. and C. Ponnamperuma, "Prebiotic Porphyrin Genesis: Porphyrins from electric discharge in ammonia, methane and water vapor.” Proc. Natl. Acad. Sci. U.S.A. 59, 22-58 (1968).

[31] Louda, J. W., Loitz, J. W., Rudnick, D. T. and E. W. Baker. "Early diagenetic alteration of chlorophyll-a and bacteriochlorophyll- $a$ in a contemporaneous marl ecosystem; Florida Bay.” Org. Chem. 31, 1561-1580 (2000).

[32] Zelmer, P. P. and E. H. Man. "Analysis of chlorophyll diagenesis-I. Kinetics of the phorbide to porphyrin transition.” Organic Chemistry, 5, 43-49 (1983).

[33] Calvin, M. and S. K. Vaughn. "Extraterrestrial life: some organic constituents of meteorites and their significance for possible biological evolution.” In: H. Kallman Bijl (Ed.) Space Res. 1, 1171-1191 (1960). 
[34] Hyatsu, R. “Orgueil Meteorite: Organic Nitrogen Contents.” Science 146, 1291-1293. (1964).

[35] Seffernick, J. L., Dodge, A. G., Sadowsky, M. J., Bumpus, J. A., and L. P. Wackett. "Bacterial Ammeline Metabolism via Guanine Deaminase.” J. Bacteriol. 192, 1106-1112 (2010).

[36] Hayatsu, R., Studier, M., Oda, A., Fuse, K. and E. Anders. “Origin of organic matter in the early solar system-II: .Nitrogen compounds.” Geochim. Cosmochim. Acta 32,175-190 (1968).

[37] Lovering, J., Private communication to R. B. Hoover. (2001).

[38] Folsome, C. E., Lawless, J., Romiez, M., and C. Ponnamperuma. "Heterocyclic compounds indigenous to the Murchison meteorite.” Nature 232, 108-109 (1971).

[39] Hayatsu, R., Studier, M. H., Moore, L. P. and E. Anders, "Purines and Triazines in the Murchison meteorite.", Geochim. Cosmochim. Acta 39, 471-488 (1975).

[40] Van der Velden, W. and A. W. Schwartz. "Search for purines and pyrimidines in Murchison meteorite.” Geochim. Cosmochim. Acta 41, 961-968 (1977).

[41] Stoks, P.G. and A. W. Schwartz. "Uracil in carbonaceous meteorites.” Nature 282, 709-710 (1979).

[42] Stoks, P. G. and A. G. Schwartz "Nitrogen-heterocyclic compounds in meteorites: significance and mechanisms of formation.” Geochim. Cosmochim. Acta, 45, 563-569 (1981).

[43] Schmitt-Kopplin, P., Gabelica, Z., Gougeon, R. D., Fekete A., Kanawati’ B., Harir, M., Gebefuegi, M., Eckel, G. and N. Hertkorn. "High molecular diversity of extraterrestrial organic matter in Murchison meteorite revealed 40 years after its fall.” Proc. Natl. Acad. Sci. 107, 2763-2768 (2010).

[44] Martins, Z., Botta, O., Fogel, M. L., Sephton, M. A., Glavin, D. P., Watson, J. S., Dworkin, J. P., Schwartz, A. W., and P. Ehrenfreund. "Extraterrestrial nucleobases in the Murchison meteorite. Earth and Planetary Science Letters 270, 130-136 (2008).

[45] Ganguly, D. and Duker, J. "Stability of DNA thymine hydrates.” Nucleic Acids Research, 19, 3319-3323 (1991).

[46] Levy, M., and S. L. Miller. "The stability of the RNA bases: implications for the origin of life.” Proc. Natl. Acad. Sci. 95, 7933-7938 (1998).

[47] Gerasimenko, L. M., Mityushina, L. L. and B. B. Namsaraevv. "Microcoleus Mats from alkaliphilic and halophilic communities.” Microbiology, 72, 71-79 (2003).

[48] Hoover, R. B. and E. V. Pikuta "CHAPTER 5: Psychrophilic and Psychrotolerant Microbial Extremophiles in Polar Environments." In Polar Microbiology: The Ecology, Diversity and Bioremediation Potential of Microorganisms in Extremely Cold Environments (Asim K. Bej, Ronald Atlas and Jackie Aislabie, Eds.), CRC Press, Taylor and Francis Group, New York. pp. 115-157 (2010).

[49] Omoregie, E. O., Crumbliss, L. L. Bebout, B. M., and J. P. Zehr. "Determination of Nitrogen-Fixing Phylotypes in Lyngbya sp. and Microcoleus chthonoplastes Cyanobacterial Mats from Guerrero Negro, Baja California, Mexico.” Appl Environ Microbiol. 70, 2119-2128 (2004).

[50] Lyngbye, H.C. (1819). Tentamen hydrophytologiae danicae continens omnia hydrophyta cryptogama Daniae, Holsatiae, Faeroae, Islandiae, Groenlandiae hucusque cognita, systematice disposita, descripta et iconibus illustrata, adjectis simul speciebus norvegicis. pp. [i]-xxxii, [1]-248, 70 pls. Hafniae [Copenhagen]: typis Schultzianis, in commissis Librariae Gyldendaliae.

[51] Kützing, F.T. (1844). Die kieselschaligen Bacillarien oder Diatomeen. pp. [i-vii], [1]-152, pls 1-30. Nordhausen: zu finden bei W. Köhne

[52] Hoover, R. B. "Those Marvelous Myriad Diatoms." National Geographic, 871-78 (1979).

[53] Ruddiman, W.F. and M.E. Raymo. "A methane-based time scale for Vostok ice.” Quaternary Science Reviews, 22, 141-155 (2003).

[54] Hoover, R. B., Pikuta, E. V., Bej, A. K., Marsic, D., Whitman, W. B., Tang, J. and P. Krader “Spirochaeta americana sp. nov., a new haloalkaliphilic, obligately anaerobic spirochaete isolated from soda Mono Lake in California.” Int J Syst Evol Microbiol 53, 815-821, (2003).

[55] Pikuta, E. V., Hoover, R. B., Marsic, D., Bej, A., Tang, J. and P. Krader “Carnobacterium pleistocenium sp. nov., a novel psychrotolerant, facultative anaerobe isolated from Fox Tunnel permafrost, Alaska.” Int J Syst Evol Microbiol, 55, 473-478, (2005).

[56] Hoover, R. B. "Comets, Carbonaceous Meteorites and the Origin of the Biosphere” in Biosphere Origin and Evolution (N. Dobretsov, N. Kolchanov, A. Rozanov and G. Zavarzin, Eds.) Springer US, New York 55-68, (2008). 